\title{
dosenvolimento QUESTAOO
}

\section{O Fazer Científico a Partir dos Grupos de Pesquisa da Área da Administração: Em Busca da Criatividade de Celso Furtado}

http://dx.doi.org/10.21527/2237-6453.2020.52.55-74

Recebido em: 1이/2019

Aceito em: 3/3/2020

Raphaela Reis Conceição Castro Silva, ${ }^{1}$ Luis Moretto Neto ${ }^{2}$

\begin{abstract}
RESUMO
A Administração caminha juntamente com a modernização da sociedade. Por isso, a ciência da Administração é vista como voltada às organizações privadas, o que é não natural e negligencia a realidade desta atividade. Este estudo coloca a ciência da Administração visando à sociedade e não às empresas capitalistas, com foco nos grupos de pesquisa de Administração vinculados à Universidade Federal de Minas Gerais (UFMG), com a intenção de apropriar e resituar as universidades públicas para resolução coletiva de problemas sociais, ligando-as com a criatividade de Celso Furtado. Este trabalho visa, então, a identificar a convergência entre tais produções e o conceito de criatividade humana. Para analisar os fatores descritos foram mapeados os grupos de pesquisa em Administração cadastradas no CNPq, localizados na UFMG. O mapeamento dos grupos foi facilitado devido ao acesso das informações contidas no site eletrônico do CNPq, no qual um total de 19 grupos e 324 artigos se adequaram aos elementos estruturantes deste estudo. Após a análise de conteúdo dos artigos, apenas um grupo de pesquisa, dentro da amostra selecionada, apresentou convergência com o conceito de desenvolvimento e criatividade humana, levando à hipótese inicial de que pouco é feito para modificar a realidade periférica a partir da ciência.
\end{abstract}

Palavras-chave: Administração. Produção científica. Desenvolvimento. Consciência crítica.

\section{THE RESEARCH GROUPS OF THE ADMINISTRATIVE SCIENCE'S: LOOKING FOR CREATIVITY BY CELSO FURTADO}

\section{ABSTRACT}

The administration walks along with the modernization of society. Hence, the science of management is seen as directed to private organizations, which is unnatural and neglects the reality of this activity. This study places the science of management aimed at society rather than capitalist enterprises, focusing on management research groups linked to the Federal University of Minas Gerais (UFMG). With the intention of appropriating and re-situating the public universities for collective resolution of social problems, linking them with the creativity of Celso Furtado. This work aims, then, to identify the convergence between such productions and the concept of human creativity. To analyze the factors described, the research groups in administration registered at CNPq, located at UFMG, were mapped. The mapping of the groups was facilitated due to the access of the information contained in the CNPq website, where a total of 19 groups and 324 articles were adapted to the structuring elements of this study. After the content analysis of the articles, only one research group within the selected sample presented convergence with the concept of development and human creativity, leading to the initial hypothesis that little is done to modify the peripheral reality from science.

Keywords: Administration. Scientific production. Development. Critical consciousness.

\footnotetext{
${ }^{1}$ Doutora em Administração pela Universidade Federal de Santa Catarina (UFSC). Professora do Instituto Federal do Rio de Janeiro (IFRJ). http://lattes.cnpq.br/2751499099289877.https://orcid.org/0000-0002-4598-9110. castroreis@gmail.com

2 Doutor em Engenharia de Produção pela Universidade Federal de Santa Catarina (UFSC). Professor titular-visitante do Programa de PósGraduação em Administração Pública da Universidade Federal de Santa Maria - UFSM. http://lattes.cnpq.br/5353000298059913. https:// orcid.org/0000-0002-8484-597X. luis.moretto.neto@ufsc.br
} 
A Administração é um fenômeno importante na sociedade moderna. Ciência que envolve múltiplas atividades produtivas, portanto o campo de estudos da Administração é um campo fértil para importantes reflexões como a proposta por este estudo.

Há certa "naturalização" da ideia de que a ciência da Administração se presta para as organizações privadas. Essa "naturalização", entretanto, é uma dissimulação de uma realidade que nada tem de natural, simplesmente por ser histórica, isto é, produzida e em transformação, negligenciando as relações de poder que ali ocorrem e naturalizando a reprodução de modelos hegemônicos.

Assim, esta pesquisa é orientada para colocar a sociedade como objeto central dos estudos organizacionais, e não as empresas capitalistas, contribuindo para oxigenar a produção do conhecimento e, sobretudo, porque isso permite a construção de ferramentas teóricas mais poderosas para a compreensão da realidade periférica que vivemos.

É intrigante observar a contradição entre o potencial de recursos do país e o baixo nível de desenvolvimento alcançado até o presente. Adentrando à questão, questiona-se como esta sociedade poderá se tornar igualitária, democrática e justa. A sociedade não se constrói sem reflexões sobre o impacto que suas ações têm no mundo. O processo de desenvolvimento, para Furtado (1978), vai além da produtividade econômica, implica necessariamente transformações sociais com reflexos no sistema de poder. Celso Furtado deixou uma enorme contribuição para pensar o Brasil e a América Latina para além das amarras da teoria econômica, principalmente em função de sua capacidade de observação histórica (DANTAS; MONFREDO, 2012). Furtado coloca na capacidade e na iniciativa humanas a possibilidade de desencadear forças que conduzam ao avanço da sociedade (VIEIRA, 2012). Nessa perspectiva, a universidade em muito pode colaborar.

Nos países periféricos e semiperiféricos, Santos (2004) defende que a busca por essa mudança deve ser protagonizada pela universidade pública, pelo Estado nacional e a sociedade civil. No âmbito das universidades, a importância das ações que venham a ser feitas em ciência, tecnologia e inovação para o desenvolvimento brasileiro é hoje evidente (CHAIMOVICH, 2000). A economia mundial depende cada vez mais da produção, da distribuição e da aplicação do conhecimento, destacando-se que $50 \%$ do PIB da maioria dos países provêm da produção das indústrias e de serviços intensivos em conhecimentos (PINTO, 2012).

O conhecimento como posto atualmente, contudo, não é capaz de alcançar tal mudança. O conhecimento é gerador de ciência, e esta se materializa por meio de tecnologias que almejam o desenvolvimento humano (BUNGE, 1980). Esse cenário seria o ideal. Percebe-se que as tecnologias privilegiam o desenvolvimento das forças produtivas que reificam o sistema capitalista, reproduzindo a dominação e exploração (GOULART; CARVALHO, 2008; LEHER, 2015). Ademais, as pesquisas brasileiras estão conectadas com os sistemas científicos das grandes potências, decorrentes da pressão neoliberal, resultando na ausência de criação de know-how e ampliando a importação de ideias e soluções, preocupação de Guerreiro Ramos já nos anos 50 (RAMOS, 1958).

Busca-se sustentar que o papel da universidade é fundamental. É indubitável que existem grupos de pesquisadores comprometidos com a transformação dos contextos sociais - no âmbito das universidades e da produção de conhecimento - que têm pro- 
curado avançar no sentido de aproximação às demandas populares, mesmo diante dos entraves burocráticos (TRAGTENBERG, 1979). Ou seja, há aqueles que desejam, de maneira efetiva, interferir na realidade histórica e social por intermédio da pesquisa. No caso da Administração, o que dizer dos professores e de seus grupos de pesquisas?

A busca por essa resposta norteará a condução deste trabalho. No Brasil, as atividades científicas desenvolvidas por equipes de pesquisadores são organizados sob a designação de grupos de pesquisa. Existem aproximadamente 5.363 grupos cadastrados no Diretório de Pesquisa do Conselho Nacional de Desenvolvimento Científico e Tecnológico da área de Ciências Sociais Aplicadas, dos quais 1.161 pertencem à área de Administração e 145 destes estão no Estado de Minas Gerais (CONSELHO..., 2017).

Isso posto, o foco de análise deste estudo serão os grupos de pesquisa de Administração vinculados à Universidade Federal de Minas Gerais, enquanto lócus relevante de produção científica e tecnológica no Brasil. A intenção, contudo, é de que este trabalho seja replicado para outras instituições que oferecem o curso de Doutorado em Administração, a partir do seguinte problema de pesquisa: Há produções científicas nos grupos de pesquisa de Administração em conexão com o conceito de criatividade humana de Celso Furtado?

Com o presente trabalho pretende-se somar algo que se acredita estar em falta no debate recente sobre as universidades. Para atender ao que foi proposto, o trabalho foi estruturado em outras quatro seções, além desta introdução. A segunda seção atenta aos fundamentos teóricos, envolvendo e relacionando a produção científica e o conceito de desenvolvimento. Na seção seguinte tratar-se-á dos procedimentos metodológicos. Na quarta seção, apresenta-se os resultados encontrados e por fim, encontram-se as considerações finais e as referências.

\section{FUNDAMENTOS TEÓRICOS}

\section{A produção científica da Administração}

Antes de tratar da produção científica da Administração, é importante retomar a trajetória histórica da constituição do curso de Graduação em Administração no Brasil, pois muito nos ajuda a compreender a realidade atual.

O curso de Administração é relativamente recente, mesmo que a atividade remonte a tempos antigos. Os Estados Unidos e a França defendem que o início do curso de Administração de Negócios deu-se ao final do século 20.

O crescimento do ensino de Administração coincide com o aumento da importância dos Estados Unidos no século XX, onde se consolida como superpotência. Este fato tem importância, especialmente, para a área de Administração de Empresas na medida em que, mundialmente se reconhece como management, é visto em grande parte uma criação norte-americana (BERTERO, 2006, p. 5).

O Brasil foi um dos primeiros países, além dos Estados Unidos, a escolarizar a Administração, criando cursos, escolas, departamentos e faculdades de Administração. Começou em São Paulo, com a Administração de Negócios, e no Rio de Janeiro, com a Administração Pública (BERTERO, 2006). 
O estabelecimento dos programas de Administração ocorreu após a Segunda Guerra Mundial, época de grande otimismo sobre o futuro. "A perspectiva era que todos os problemas da humanidade solucionar-se-iam pelo desenvolvimento econômico que traria no seu bojo também o desenvolvimento social e político" (BERTERO, 2006, p. 6). Um quadro institucional internacional foi criado com o objetivo de promover a paz e o desenvolvimento econômico com o Banco Mundial, FMI, Unesco, FAO, OMS, OIT (BERTERO, 2006).

De acordo com Alcadipani e Bertero (2014), é possível elencar três instituições que tiveram um papel de destaque na exportação desse produto, chamado management, para o Brasil nas décadas de 50 e 60. A primeira instituição é a missão diplomática dos Estados Unidos no Brasil, que enviou ajuda financeira para a Escola de Administração de Empresas de São Paulo (Easp), para a Universidade Federal do Rio Grande do Sul (UFRGS) e para a Universidade Federal da Bahia (Ufba).

$\mathrm{O}$ Institute of Inter-American Affairs e a Michigan State College of Agriculture and Applied Sciences (MSU) desempenharam também um papel fundamental, com um contrato entre as duas instituições para que houvesse um apoio à Fundação Getulio Vargas na condução de uma escola de negócios no Brasil. O objetivo do Institute of Inter-American Affairs era de melhorar a imagem dos Estados Unidos na América Latina em um contexto de pré-Segunda Guerra Mundial, e a MSU tinha o ideal norte-americano de levar o "progresso" ao mundo mediante a criação de uma escola de negócios no Brasil que deveria servir de centro difusor no país (ALCADIPANI; BERTERO, 2014). A imagem do profissional administrador de empresas estava associada à imagem de modernidade, da mudança e do alinhamento do país com as nações que se modernizavam (BERTERO, 2006).

Por último, a Fundação Ford, criada por Henry Ford I, financiou junto com o Conselho Nacional de Desenvolvimento Científico e Tecnológico (CNPq) atividades relacionadas à expansão do management no Brasil.

Na década de 40 a Universidade de São Paulo também criou a Faculdade de Ciências Econômicas e Administrativas, com foco maior na área da Economia. Foi no final dos anos 50 que se fortaleceu a área de Administração, com a criação do curso de Graduação. O curso baseava-se em dois grandes eixos: o primeiro era predominantemente composto pelas disciplinas das Ciências Sociais, como Sociologia, Ciência Política, Antropologia, Psicologia, Direito e Economia. O segundo eixo ensinava as áreas funcionais da Administração (finanças, marketing, contabilidade gerencial, administração de pessoas, vendas, produção, etc.). Como salienta Bertero (2006), este eixo visava à profissionalização do administrador como modernizadora, posto que a atividade econômica do país era bem mais modesta do que em outros países mais desenvolvidos economicamente. Os currículos elaborados pela Easp e pela FEA, derivados dos modelos norte-americanos, posteriormente foram utilizados como exemplo para o estabelecimento de currículo mínimo nos cursos que foram criados a partir dos anos 60.

Desde a década de 20 as grandes corporações anônimas norte-americanas contavam com administradores profissionais e esse fato influenciou fortemente a criação do curso de Graduação, bem como os cursos de MBA que surgiram a seguir. A partir dessa realidade e da necessidade de governança estendeu-se a escolarização da Administração naquele país. Esse modelo acionário não se alastrou no Brasil, bem como em outras 
economias europeias e asiáticas. O Brasil só passou a ter grandes empresas a partir da segunda metade do século passado. O motivo, portanto, da difusão do administrador para essas economias ligou-se à competência necessária que deveria ser escolarizada (BERTERO, 2006).

Os cursos de Pós-Graduação foram instituídos na área de Administração no início da década de 70 e coincidiram com o movimento de institucionalização do ensino em nível de Pós-Graduação no Brasil (BERTERO, 2006).

$\mathrm{Na}$ década de 60 o Parecer do Conselho Federal de Educação (CFE) criou a distinção entre "lato sensu" e "stricto sensu". Esta última visa à formação de profissionais acadêmicos (professores e pesquisadores), enquanto o primeiro visa ao aprimoramento dos que se dedicam ao exercício da profissão. Essa distinção, contudo, ainda apresentava algumas confusões nas chamadas áreas aplicadas, das quais a Administração é um exemplo, pois os cursos de Pós-Graduação em Administração se viabilizaram com um corpo discente misto, incluindo profissionais e acadêmicos. Esta mescla terminou mais tarde, à medida que critérios originados na própria comunidade científica e executados por intermédio da Capes acabaram por forçar a separação efetiva (BERTERO, 2006).

Na metade da década de 70 a área de Administração teve um importante apoio financeiro da Financiadora de Estudos e Projetos (Finep), que viabilizou programas na Fundação Getulio Vargas de São Paulo; no Instituto de Pós-Graduação e Pesquisa em Administração na Universidade Federal do Rio de Janeiro; na Fundação João Pinheiro, da Universidade Federal de Minas Gerais e no Programa de Pós-Graduação da Universidade Federal do Rio Grande do Sul.

Essas instituições e seus programas tornaram-se focos para a formação de mestres - e posteriormente doutores - que acabaram assumindo posições em outros programas em universidades públicas e privadas de todo o país. As primeiras instituições a oferecerem o curso de Pós-Graduação foram a Universidade de São Paulo e a Fundação Getulio Vargas em São Paulo, com programas de Mestrado. Posteriormente foram criados os programas de Doutorado (BERTERO, 2006).

O crescimento da Pós-Graduação no Brasil está ligado à reforma da universidade brasileira em 1969, que entre outras providências adotadas pelo legislador extinguiu a cátedra vitalícia pelo departamento de ensino e pesquisa, bem como a figura do catedrático pela carreira docente estruturada em vários níveis, desde o instrutor de ensino até o professor titular. Assim, com a exigência pela titulação do corpo docente, salientada também pela avaliação institucional das IESs, a demanda pelos cursos de Mestrado e Doutorado aumentou. Dados da Capes (COORDENAÇÃO..., 2016) mostram que no ano de 2014 foram titulados 44.502 estudantes no Mestrado, 16.745 no Doutorado e 5.727 no Mestrado Profissionalizante. Além do crescimento de alunos e cursos de Pós-Graduação, houve uma expansão de encontros como congressos, convenções, conferências, que acontecem frequentemente nos dias atuais (BERTERO, 2006).

Foi esta a lógica da difusão e legitimação do profissional de Administração de Empresas no Brasil: aumento do tamanho das instituições, que incapacitava seus proprietários em dirigi-las sozinhos, e a ampliação da competitividade, que exigia desempenhos superiores, tornando o administrar um conjunto de técnicas obtido pelo conhecimento e pela experiência. Nas palavras de Sole (2004, p. 5), 
o personagem do administrador apareceu ao mesmo tempo que um novo tipo de organização: a empresa moderna, que emerge nos Estados Unidos, em torno dos anos 1915-1920. Como outros, ele fala da "revolução administrativa" a propósito da passagem do "capitalismo empreendedor" ao "capitalismo administrativo": a direção da empresa passa das mãos do empreendedor capitalista (fundador e proprietário) àquelas dos "administradores" assalariados.

Assim, o administrador é um ator fundamental da modernidade, pois a "administração significa possibilidade e necessidade de dirigir racionalmente a empresa" (SOLE, 2004, p. 5). Este é um "herói" conduzido pela razão, devendo dirigir racionalmente a empresa, tendo em vista a dinâmica da sociedade atual que se baseia em três grandes pilares: "(1) a hegemonia do econômico, (2) o culto da empresa, (3) a influência crescente do pensamento empresarial sobre as pessoas" (CHANLAT, 1996, p. 15).

Essa cultura se caracteriza por aspectos como foco no curto prazo, lógica pragmática, abordagem triunfalista na apresentação de tecnologias gerenciais, valorização do adestramento em detrimento da aprendizagem e exaltação da novidade (BARBOSA, 2003). Assim,

o managerialismo, isto é, o sistema de descrição, de explicação e de interpretação do mundo a partir das categorias da gestão está profundamente bem instalado na experiência social contemporânea. Ele é, diretamente, o produto de uma sociedade de gestores que busca racionalizar todas as esferas da vida social (CHANLAT, 1996, p. 17).

Um problema, segundo Motta (1983), que ainda vigora atualmente, é a pouca ênfase em análises críticas da realidade das faculdades de Administração, o que provoca um isolamento de especialistas e uma formação frequentemente deficiente dos estudantes. Por isso, pensar na formação superior em Administração, muitas vezes, é tentar compreender como o aluno é formatado para reproduzir e manter a ordem hegemônica da instrumentalização excessiva dos cursos. De acordo com Nicolini (2003, p. 50), os cursos de Administração foram concebidos dentro de uma lógica mecanicista, "de determinadas ações ou causas derivarão determinados efeitos ou conseqüências previsíveis, dentro de uma correlação razoável".

Nesse sentido, "se for adotada uma perspectiva do mercado, não resta dúvida de que os clientes estão satisfeitos, a julgar pelo vigor, crescimento e resultados apresentados pela indústria administrativa [revistas especializadas, encontros]" (BERTERO, 2006, p. 30). Por outro lado, a realidade social brasileira continua segmentada pela larga diferença social e pela baixa qualidade de vida da população.

Desde o início percebeu-se a necessidade de materiais que tratassem da realidade brasileira. Desta forma, surgiram as primeiras manifestações por meio de publicações em revistas de pesquisa. A Escola de Administração da Fundação Getulio Vargas iniciou a publicação da Revista de Administração de Empresas (RAE) e também a Revista do Serviço Público (RSP) (BERTERO, 2006).

A intensificação das atividades de pesquisa em Administração, todavia, só ocorreu quando se institucionalizou a Pós-Graduação stricto sensu. Esse modelo proclama a inseparabilidade entre ensino e pesquisa. O curso de Pós-Graduação stricto sensu, diferentemente da Graduação, não visa a preparar pessoas para o exercício profissional, mas sim para pesquisar e publicar, além de assegurar a formação de professores universitários (BERTERO, 2006). O rápido e crescente número de programas de Pós-Graduação 
stricto sensu é um elemento fundamental ao se refletir sobre a qualidade e a quantidade de publicações científicas no Brasil, desde o final da década de 60 (BERTERO; CALDAS; WOOD Jr., 1999).

Assim como ocorreu na Graduação, os Estados Unidos influenciaram fortemente a formatação da Pós-Graduação no Brasil: (1) mestres e doutores devem ser treinados em pesquisa e formar os quadros docentes da universidade; (2) cursos devem se estruturar em torno de linhas de pesquisa; e (3) julgamento e avaliação dos programas são realizados em função das linhas de pesquisa, suas consistências e produtividades (BERTERO, 2006).

O sistema de avaliação da Capes passou a avaliar o curso de Administração apenas no final da década de 90 . Esse sistema atribui grande importância a pesquisas que resultem em publicações. Embora outros critérios sejam avaliados - orientação de mestrandos e doutorandos, projetos de pesquisa, projetos de extensão, entre outros - o maior peso é atribuído a publicações resultantes em periódicos bem qualificados, que podem ser de autoria dos docentes e também de discentes do programa de Pós-Graduação stricto sensu (BERTERO, 2006).

Uma publicação científica é avaliada pelos pares que têm a identidade mantida em sigilo pela editoria do periódico. Normalmente o material que chega recebe críticas, comentários e sugestões até que se tenha um texto considerado publicável (BERTERO, 2006). Bertero, Caldas e Wood Jr. (1999), contudo, indicaram que há uma grande diversidade quanto aos critérios de avaliação das publicações científicas em Administração no Brasil.

A avaliação realizada pela Capes julga a produção científica brasileira pelo grau de inserção junto a comunidade acadêmica mundial, ou seja, publicações em periódicos acadêmicos de nível internacional e apresentação de trabalhos em congressos internacionais de primeiro nível (BERTERO; CALDAS; WOOD Jr., 1999).

- Bertero (2006) afirma que a agenda de pesquisa do pesquisador em Administração é bastante ampla. Pode-se encontrar:

- Pesquisas que permitam conhecer a realidade administrativa brasileira.

- Pesquisas que verificam até que ponto o que se faz aqui é dotado de originalidade e se afasta das teorias predominantes.

- Pesquisas que tenham aplicações na prática administrativa, auxiliando na meIhoria da qualidade da administração no Brasil e

- Pesquisas que verificam as consequências da teoria para a prática da Administração.

- Bertero et al. (2013) apresentam uma análise da produção na década de 2000 na Administração. Esse estudo aponta ainda para a necessidade latente de conectar os estudos à realidade brasileira.

Nas ciências administrativas, portanto, a expansão global da academia e do conhecimento intensificou a hegemonia anglo-americana ao fortalecer uma tendência de integração e pretensa universalização, inibidora de uma produção local que a desafie. É preciso redefinir o valor do conhecimento científico como bem comum. De escrever sobre temáticas que interessam a cada país, aproximando da realidade brasileira e encontrando a pertinência sociocultural. O campo científico dispõe de uma autonomia que interfere diretamente no estado da relação de forças, nas lutas entre os detentores de poder (BOURDIEU, 1996). 
Considera-se, assim, que, apesar dessas constatações, a universidade pode se constituir como um dos mecanismos de promoção da democracia, da igualdade, da cidadania e da justiça social graças à transmissão de saberes. Assim, buscar-se-á primeiramente (re)pensar a relação entre a pesquisa científica em Administração e o desenvolvimento, a partir da perspectiva teórica de Celso Furtado.

\section{Celso Furtado e a Criatividade Humana}

O conceito de desenvolvimento é multifacetado e relativo ao seu tempo e espaço, portanto não é um constructo absoluto, nem neutro, mas sim construído historicamente e moldado pelas forças políticas, econômicas e científicas da sociedade. Assim, o conceito de desenvolvimento é complexo. Em todos os espaços fala-se em desenvolvimento, mas nem sempre está claro seu significado e implicações. Adicionalmente, deve-se ter em vista que "o conceito de desenvolvimento, como numerosos produtos da ciência, tem sofrido as vicissitudes da absorção pelos mais diferentes discursos ideológicos" (CUNHA, 1980, p. 15).

O conceito de desenvolvimento vem sendo construído com base em três visões paradigmáticas: desenvolvimento como crescimento econômico, desenvolvimento como satisfação das necessidades básicas e desenvolvimento como elemento de sustentabilidade socioambiental. Para compreendê-lo, portanto, Santos et. al (2012) sugerem o apoio em quatro dimensões de análise: política, econômica, social e ambiental, tendo em vista que estas dimensões estão presentes e se relacionam simultaneamente.

Assim, pode-se agrupar os estudos sobre desenvolvimento por meio de oito abordagens teóricas, conforme Quadro 1.

Quadro 1 - Abordagens teóricas sobre desenvolvimento

\begin{tabular}{|c|c|l|c|}
\hline Abordagem & Autores & \multicolumn{1}{|c|}{ Obra } & Ano \\
\hline \multirow{2}{*}{ Clássica } & Adam Smith & A Riqueza das Nações & 1776 \\
\cline { 2 - 4 } & David Ricardo & $\begin{array}{l}\text { Princípios de Economia Política e } \\
\text { Tributação }\end{array}$ & 1817 \\
\hline \multirow{2}{*}{ Marxista } & Karl Marx & O Método da Economia Política & 1859 \\
\cline { 3 - 4 } & O Capital & 1867 \\
\hline \multirow{2}{*}{ Schumpeteriana } & Joseph Schumpeter & Teoria do desenvolvimento econômico & 1911 \\
\cline { 3 - 4 } & Capitalismo, Socialismo e Democracia & 1942 \\
\hline \multirow{2}{*}{ Keynesiana } & John M. Keynes & $\begin{array}{l}\text { A teoria geral do emprego, do juro e da } \\
\text { moeda }\end{array}$ & 1936 \\
\hline \multirow{2}{*}{ Institucionalista } & $\begin{array}{c}\text { Celso Furtado, Enzo } \\
\text { Falleto, Fernando } \\
\text { Henrique Cardoso, } \\
\text { Raul Prebisch. }\end{array}$ & Publicações da Cepal & 1899 \\
\cline { 2 - 4 } & Thorstein Veblen & A teoria da classe ociosa & 1934 \\
\cline { 2 - 4 } & Wesley Mitchell & Economia Institucional & 1927 \\
\hline \multirow{2}{*}{ Da sustentabilidade } & ONU & Relatório Brundtland & 1987 \\
\cline { 2 - 4 } & ONU & Agenda 21 & 1995 \\
\hline \multirow{2}{*}{ Pós- } & Arthuro Escobar & La Invención del Tercer Mundo & 1948 \\
\hline
\end{tabular}

Fonte: Elaborado pelos autores (2019). 
Tendo em vista as abordagens citadas, bem como a escolha epistemológica dos autores, nossa intenção é apreender como Celso Furtado ${ }^{3}$ apresenta a genealogia do desenvolvimento e verificar quais as possibilidades e os caminhos indicados para ensejar uma transição ao desenvolvimento nacional e autônomo. As décadas de 50 e 60 foram marcadas por obras que orientaram o pensamento brasileiro e a formulação de políticas públicas em diferentes segmentos e levaram a um desenvolvimento dinâmico (VIEIRA, 2012). De acordo com Bertero (2006), cientistas que explicaram nossa situação de subdesenvolvimento foram: Celso Furtado, Caio Prado Júnior, Florestan Fernandes, Fernando Henrique Cardoso, Otavio Ianni e Hélio Jaguaribe. Os textos desses autores foram referências para as primeiras turmas de Administração.

Tal escolha deve-se, pois, ao fato de que o teórico latino-americano atentou-se para além da ênfase na evolução do sistema produtivo e de acumulação de capital, para as condições sociais da produção, contribuindo, assim, para que a dimensão social ganhasse relevância no conceito de desenvolvimento. Para Dantas e Monfredo (2012), Furtado foi mais um intelectual indispensável para compreender a História brasileira do que propriamente um economista, tendo em vista sua grande capacidade criativa. Seus estudos não eram baseados em teorias gerais ou leis formuladas pela economia, mas buscavam considerar as problemáticas sociais e políticas, tendo em vista aplicação do método histórico (DANTAS; MONFREDO, 2012). Assim, é um pensador de questões que vão além da economia (FREIRE D’AGUIAR, 2013).

Celso Furtado teve uma sólida formação acadêmica e sua extensa e profunda obra o fizeram um intelectual admirado e respeitado (VIEIRA, 2012). Além disso, tomou para si o desafio de compreender as razões do nosso atraso, considerando-se as potencialidades do Brasil, visando a um desenvolvimento mais justo e includente (FURTADO, 2002; LEITÃO, 2015) e assim contribuir para a compreensão sistemática dos aspectos gerenciais mais amplos das sociedades (CRISTALDO, 2015). Ademais, Celso Furtado é notoriamente mais conhecido no âmbito dos estudos econômicos, e pouco no campo da cultura. Segundo Leitão (2015) e Vieira (2012), o pensamento de Furtado sobre os significados da cultura e da criatividade sobre o desenvolvimento continua bastante atual.

A perspectiva em tela consiste em retomar o esforço elaborado por Celso Furtado, visando a romper a situação periférica das civilizações latino-americanas. Vale salientar que tal mergulho histórico em suas contribuições foram imprescindíveis para a compreensão das nuances da construção teórica deste intelectual. Dito isso, o conceito apreendido será aquele apresentado em sua obra "Criatividade e dependência na civilização industrial", de modo que se encontra um elemento importante no sentido da

\footnotetext{
${ }^{3}$ Celso Furtado nasceu na Paraíba em 1920. Formou-se em Direito e posteriormente especializou-se em Ciências Econômicas. Doutorou-se pela Universidade de Sorbonne em 1948. Destacou-se como economista a partir de sua atuação na Cepal em 1949, onde conviveu com outro grande economista, Raul Prebisch (DANTAS; MONFREDO, 2012). Em decorrência dos paradigmas econômicos da época, a escola da Cepal, onde Celso Furtado levantava a bandeira de um modelo próprio de desenvolvimento para a América Latina. Suas principais obras na área de economia: Uma economia dependente (1956); Formação Econômica do Brasil (Fondo de Cultura, 1959; e, pela Companhia das Letras, em 1976, 1991 e 2007, totalizando 72 edições); Desenvolvimento e subdesenvolvimento (1961); Dialética do desenvolvimento (1964); Subdesenvolvimento e estagnação na América Latina (1966); Formação Econômica da América Latina (1969); A economia latino-americana (1976, 2007); Introdução ao desenvolvimento (2000); Capitalismo global (2000); Em busca de um novo modelo (2002), entre outras obras importantes (VIEIRA, 2012).
} 
concepção, defendida por Celso Furtado, relativa ao processo de desenvolvimento: a criatividade. A política cultural, para Furtado, teria por finalidade liberar as forças criativas da sociedade, que teve grande influência do intelectual Amartya Sen (LEITÃO, 2015).

Com o aumento da complexidade do sistema econômico, a criatividade alcança um papel crescente. Para dar esse papel à criatividade é preciso “(...) ter em conta não apenas a racionalidade dos meios mas também a dos fins" (FURTADO, 1978, p. 87), tendo em vista que quanto mais diversificado é o produto final, mais difícil é pensá-lo em termos de produtividade física do trabalho.

Assim, "criatividade" significava a capacidade de transformar globalmente o horizonte do progresso da vida social, abrindo o espaço à constituição de novas formas de vida (SAFATLE, 2015, p. 71). Isso posto, "o conceito de criatividade teria necessariamente de ser elevado a eixo central da análise social" (2015, p. 71), para assim identificar as necessidades fundamentais da coletividade e as possibilidades de avanço da ciência e da técnica.

Considerando-se que, segundo Cohn (2015, p. 29),

(...) a ideia de desenvolvimento não pode ser reduzida a conceito meramente descritivo de um estado de coisas, mas aponta para objetivo a ser perseguido. Tem caráter normativo para além de estritamente analítico. Isso significa que nela se encontra um princípio de avaliação de formas de organização e de políticas mais do que um esquema de exposição e análise de processos em curso.

Dentro dessa perspectiva, a ideia de desenvolvimento vai além da eficácia do sistema produtivo, que reproduz uma sociedade desigual e de elevado potencial de acumulação, para poucos, nas nações periféricas. A visão sobre o desenvolvimento amparada em variáveis quantitativas, para Furtado, nunca levariam a uma real transformação. Destarte, os indicadores de renda ou produto per capita, produtividade social dos fatores de produção, se desvinculam das discussões sobre a desigualdade social (FURTADO, $1978,1980)$. E tais indicadores estão contidos no conceito de desenvolvimento. Furtado (1980) alerta que os fatores econômicos são condições necessárias ao desenvolvimento, mas não exclusivamente.

A dimensão do desenvolvimento e do crescimento são distintas, pois, para o crescimento "(...) prevalecem os princípios da eficiência e da rapidez de resposta" (COHN, 2015, p. 26), e para o desenvolvimento “(...) prevalecem a deliberação e a reflexividade" (p. 26). O processo de desenvolvimento, na percepção de Furtado (1978), vai além da produtividade econômica, implica necessariamente transformações sociais com reflexos no sistema de poder. Tomando como exemplo os países que lideraram na evolução da civilização industrial, Furtado (1978, p. 60) afirma que "[estes] desde o início [eram] diretamente orientados para o desenvolvimento das forças produtivas, a acumulação propiciou outras transformações sociais que tornariam viável a crescente integração política da massa de assalariados. A homogeneização das formas de vida ocorreria no que concerne à satisfação das necessidades básicas (inclusive no campo da cultura não-material) (...). Os bens coletivos, de crescente importância na definição do estilo de vida, seriam um fator de homogeneização social, ainda que em grau que varia consideravelmente entre países". 
Com efeito, Furtado acredita na instituição de uma política consciente e ousada de fomento à criatividade humana e de controle dos recursos não renováveis, de grande valor econômico e de dinamização do mercado interno nos países periféricos. A par disso, a criatividade humana canalizada e posta a serviço do desenvolvimento das forças produtivas e da diversificação dos padrões de vida da coletividade é elemento indispensável na luta contra a dependência. Os países periféricos podem tirar proveito e ter acesso ao mercado das nações dependentes, a partir do controle dos recursos não renováveis de grande valor econômico, que é uma das principais fontes de poder nas relações internacionais. Assim, torna-se possível acumular recursos financeiros necessários para afirmar posições e ampliar o campo de resistência à dominação estrangeira (ALMEIDA, 2009).

Em suma, na visão de Furtado, para superar a dependência externa as economias periféricas deveriam lançar uma política audaciosa de investimento em capital humano e de recuperação da autonomia nacional, via valorização da criatividade humana e na defesa dos recursos naturais não renováveis.

\section{MÉTODOS E PROCEDIMENTOS}

Nesta seção serão abordadas as ações metodológicas indispensáveis para a execução desta pesquisa, especificamente seu tipo, a definição de seu objeto, técnicas que foram usadas para a coleta de dados e suas posteriores análises, com o objetivo de identificar a convergência entre as produções científicas e o conceito de criatividade humana de Celso Furtado.

A pesquisa pode ser caracterizada como descritiva, pois busca conhecer a realidade estudada, suas características, seus problemas. Quanto à abordagem, a presente pesquisa classifica-se como qualitativa, pois pretende avaliar a qualidade das informações e ter acesso à percepção dos atores. Cumpre salientar que se deve rejeitar a falsa dicotomia entre a separação dos estudos qualitativos e quantitativos (GOODE, HATT, 1972; VIEIRA, 2012), pois as questões fundamentais são aquelas relacionadas com a precisão, fidedignidade e relevância dos dados e suas análises. Assim, este trabalho utilizou também dados quantitativos para melhor ilustrar as características predominantes na pesquisa científica da Administração.

Inicialmente mapeou-se os grupos de pesquisas existentes no Estado de Minas Gerais. Destaca-se que o critério de escolha de tais grupos foi o credenciamento em programas de Pós-Graduação em Administração com curso de Doutorado. Sendo assim, duas instituições atendem aos nossos critérios: a Universidade Federal de Lavras (Ufla) e a Universidade Federal de Minas Gerais (UFMG), contudo a Universidade Federal de Lavras foi desconsiderada, para garantir a neutralidade das análises, uma vez que a pesquisadora já estudou lá.

Em outubro de 2017 fora acessado o site eletrônico do Diretório de Grupos de Pesquisa vinculados ao CNPq e realizada a coleta de informações sobre a UFMG acerca dos seus grupos de pesquisa, a saber, nome do grupo, líder e segundo líder dessa universidade pública, totalizando 25 grupos. A seguir foi acessada a página do Programa de Pós-Graduação em Administração da Universidade Federal de Minas Gerais para verificar se o líder do grupo de pesquisa está credenciado ao referente programa. 
Na primeira etapa procedeu-se à pesquisa documental e classificação da produção científica dos grupos de pesquisas. A partir do nome do grupo, bem como de seu líder, buscou-se na Plataforma Lattes a produção de artigos científicos, tendo os seguintes critérios para a seleção: (a) tempo: recorte temporal de dez anos, compreendendo os trabalhos de 2006-2016; (b) natureza: publicações em periódicos da área de Administração conforme Qualis 2015; (c) autoria: de pelo menos dois componentes dos grupos, incluindo o líder e (d) tipo: artigos empíricos (sendo assim, ensaios teóricos foram excluídos).

Com tais informações foram excluídos: cinco grupos por estarem com informações desatualizadas no Diretório de Grupos de Pesquisa vinculados ao CNPq; um grupo, no qual o líder mudou da área da Administração para a Psicologia, e dois grupos que não tinham produções científicas com integrantes do grupo. Sendo assim, foram coletados 303 artigos de 19 grupos de pesquisa restantes.

Posteriormente a esse mapeamento, os 303 artigos foram submetidos à caracterização conforme as categorias de análise elaboradas, a partir de uma análise livre, e consequentemente não exaustiva, do conceito de desenvolvimento e criatividade humana de Furtado (1978). As categorias analíticas são: objeto de estudo, posicionamento estatal, lógica, horizonte, caráter, perspectiva desenvolvimentista e temática: (a) quanto ao objeto de estudo buscou identificar se trata de empresas privadas (agentes diretamente empenhados na acumulação) ou empresas sociais (agentes que lutam pela valorização do trabalho, ou seja, por difundir socialmente os frutos da crescente produtividade do trabalho que engendra a acumulação); (b) quanto ao posicionamento do Estado no que tange ao desenvolvimento sob sua tutela ou tutela das empresas; (c) quanto à lógica apresentada predominantemente revelando os meios ou fins (condição necessária para a criatividade); (d) sobre o horizonte do trabalho, voltado para as necessidades fundamentais da coletividade (processo de apropriação do excedente e seus impactos na divisão social do trabalho e na estratificação e dominação sociais) ou individuais (o processo de acumulação e ampliação da capacidade produtiva); (e) quanto ao caráter, normativo (avaliação de formas de organização ou de políticas) ou estritamente analítico (esquema de exposição e análise de processos em curso); (f) quanto à perspectiva do desenvolvimento apresentada (prevalecem a deliberação e a reflexividade; transformações sociais com reflexos no sistema de poder; integração política da massa de assalariados) ou crescimento (variáveis quantitativas - indicadores de renda ou produto per capita, produtividade social dos fatores de produção, os princípios da eficiência e da rapidez de resposta, produtividade econômica; (g) e por fim, a temática tratada, buscando encontrar aqueles trabalhos que tratam da instituição de uma política consciente e ousada de fomento à criatividade humana e de controle dos recursos não renováveis de grande valor econômico e de dinamização do mercado interno nos países periféricos.

Nesse momento, toda a produção científica de autoria dos grupos foi lida e analisada, seguindo os preceitos da análise de conteúdo (BARDIN, 2011), visando à exploração do material com vistas à identificação das dimensões analíticas, numa espécie de emparelhamento entre a teoria de Furtado (1978), com especial ênfase aos conceitos de desenvolvimento e criatividade humana. 


\section{APRESENTAÇÃO E ANÁLISE DOS DADOS}

Nessa etapa, o objetivo era identificar a convergência entre as produções científicas dos grupos de pesquisa selecionados e o conceito de criatividade humana de Celso Furtado, a partir das sete categorias analíticas definidas na seção anterior. Essa análise trouxe alguns indicativos sobre as características da produção científica da área da Administração. Obviamente, tais resultados não podem ser generalizados, mas trazem pistas sobre algumas lacunas e desafios da nossa área. Organizamos os dados em gráficos que ilustram com maior clareza o que encontramos na empiria.

Gráfico 1 - Categoria Analítica: Objeto de Estudo

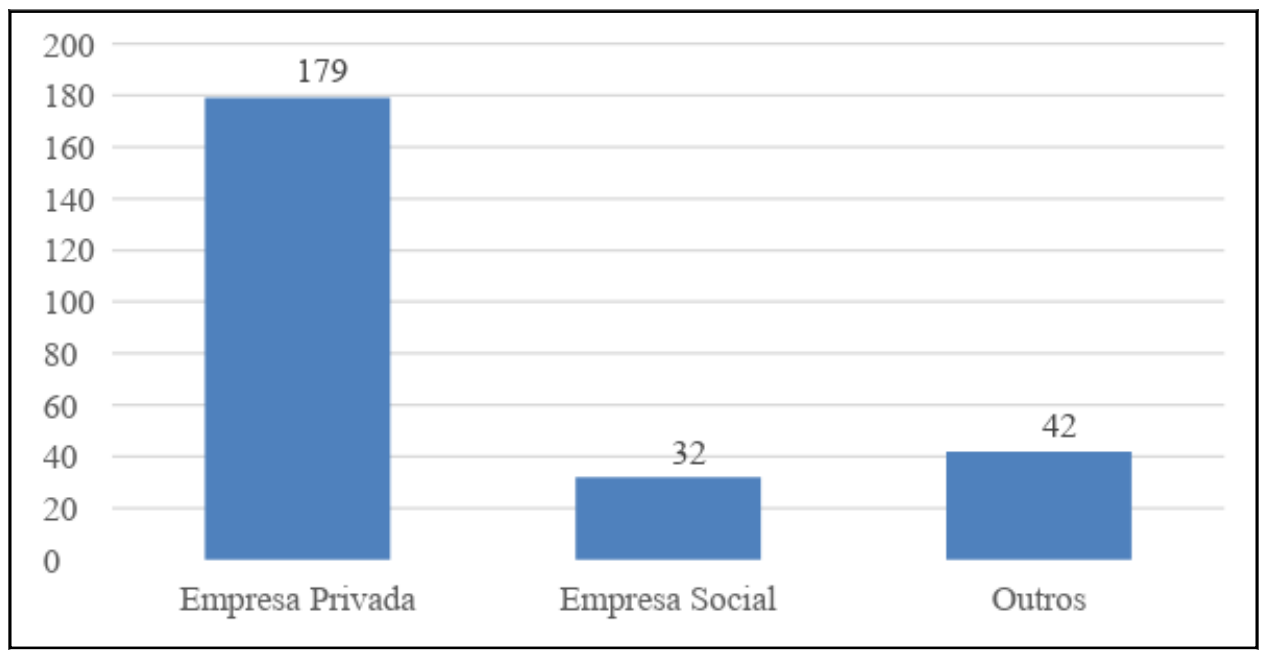

Fonte: Elaborado pelos autores (2019).

O Gráfico 1 evidencia que o objeto de pesquisa mais estudado é a empresa privada, local em que se concentra o poder político e econômico nos países periféricos (GOULART; CARVALHO, 2008). Nesse sentido, pode-se coadunar com as ideias das autoras de que a ciência está alienada devido à determinação social dos objetivos de sua própria atividade, pois se submete aos ditames materiais e objetivos de produção do órgão reificado de controle, ou seja, do capital.

Ao retomar a trajetória dos cursos de Administração no Brasil, sabe-se que o estabelecimento dos programas de Administração ocorreu após a Segunda Guerra Mundial, época de grande otimismo sobre o futuro. Surge assim a figura do administrador, como herói da modernidade, capaz de gerenciar grandes empresas e aumentar a competitividade (SOLE, 2004). Esse movimento justifica, de certa forma, tal resultado.

De sorte que o predomínio do objeto de estudo - empresas privadas - decorre da trajetória histórica de criação dos cursos de Administração e de sua regulamentação bem como do poder político e econômico que estas exercem na nossa sociedade. Há certa "naturalização" da ideia de que a ciência da Administração se presta para as organizações privadas. Essa "naturalização", entretanto, é uma dissimulação de uma realidade que nada tem de natural, simplesmente por ser histórica, isto é, produzida e em transformação, negligenciando as relações de poder que ali ocorrem e reproduzindo modelos hegemônicos. 
Gráfico 2 - Categoria Analítica: Posicionamento Estatal

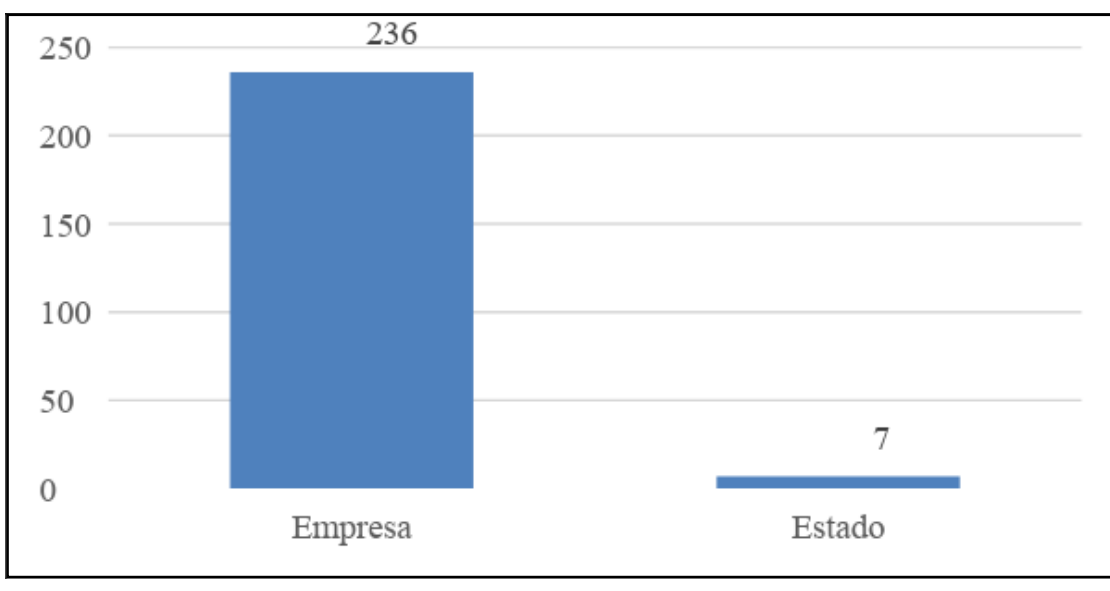

Fonte: Elaborado pelos autores (2019).

A segunda dimensão analisada foi quanto ao posicionamento estatal que os autores adotaram nos artigos. Conforme apresenta o Gráfico 2, há o predomínio da profissionalização do Estado e poucos tratam do fortalecimento deste para atender os anseios da sociedade. De certa forma, isso indica a força das doutrinas econômicas pró-mercado neoliberais dentro da produção científica da Administração.

Diante das desilusões vivenciadas pela América Latina nos anos 70 e 80, a ideologia neoliberal, preconizando a diminuição da intervenção estatal na economia, por meio dos processos de privatização, da abertura de mercado e da livre circulação de capital, recebeu o apoio da política econômica mundial e da Academia (CARNEIRO, 2006). Para Furtado (2004), contudo, a doutrina neoliberal levou o Brasil ao endividamento, e consequentemente comprometeu sua governabilidade.

$O$ conceito de desenvolvimento, que aqui se defende, precisa de um Estado forte e capaz de instituir políticas conscientes e ousadas de fomento à criatividade humana e de controle dos recursos não renováveis, de grande valor econômico e de dinamização do mercado interno nos países periféricos. Assim, tal perspectiva não foi encontrada, majoritariamente, na produção científica analisada.

Gráfico 3 - Categoria Analítica: Lógica

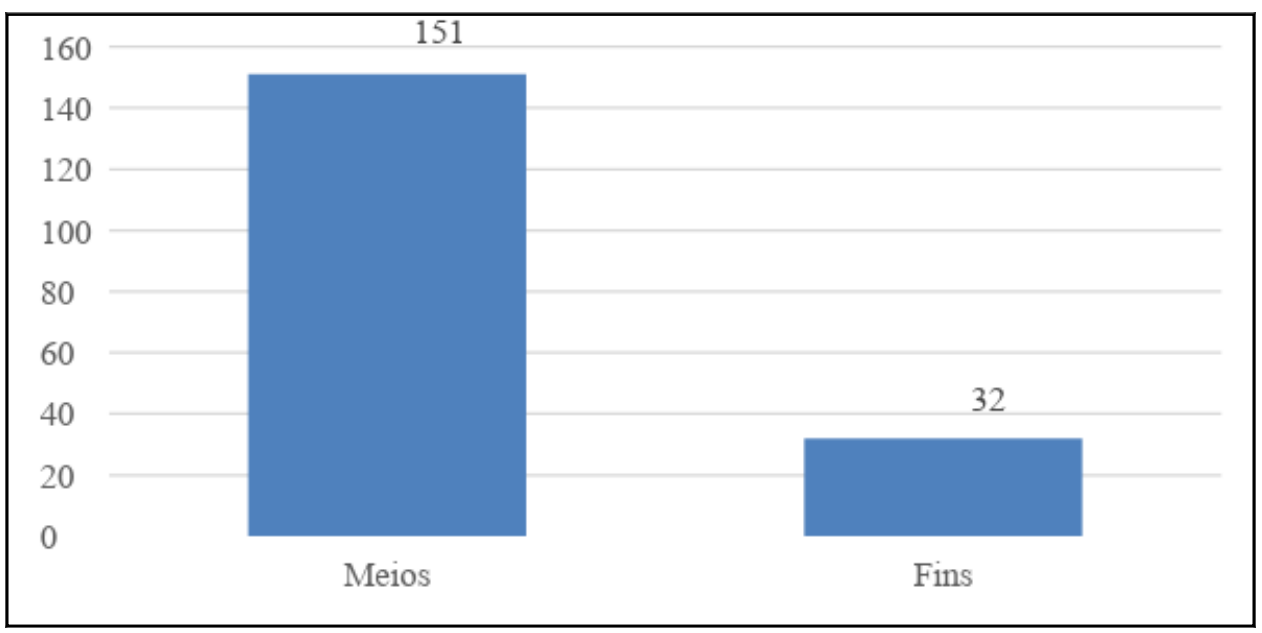

Fonte: Elaborado pelos autores (2019). 
A terceira dimensão focou na racionalidade dos meios e dos fins, como condição necessária ao processo de criatividade, como elemento do desenvolvimento. Para dar esse papel à criatividade é preciso "(...) ter em conta não apenas a racionalidade dos meios, mas também a dos fins" (FURTADO, 1978, p. 87). Houve o predomínio da lógica dos meios sob a perspectiva de instrumentalização da gestão para o alcance dos fins nos trabalhos avaliados dos grupos de pesquisas. Em outros termos, foram apenas 17,48\% dos trabalhos que se debruçaram sobre outra lógica para além dos fins de atingimento da produtividade e lucratividade.

Tal resultado expõe que a produção científica prioriza os meios de tornar a realidade administrativamente mais eficiente e eficaz, levando à melhoria do desempenho dos administradores e da qualidade da Administração. Diferentemente da proposta de Celso Furtado quando se trata de um projeto de mudança para o país com fomento à criatividade.

Gráfico 4 - Categoria Analítica: Horizonte

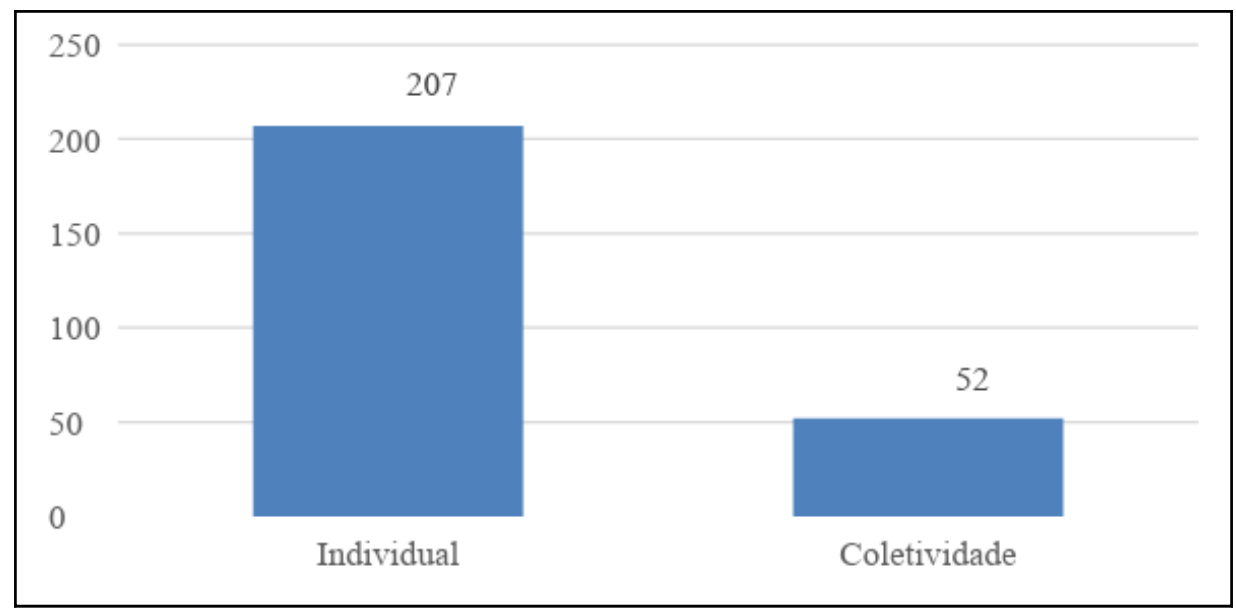

Fonte: Elaborado pelos autores (2019)

A quarta dimensão analisada foi sobre os horizontes - individual ou coletivo da produção científica. O resultado apresenta uma coerência com os anteriores, pois uma vez que a maioria dos trabalhos trata de empresas privadas, com foco nos meios, sua preocupação central está em atender às necessidades individuais, quais sejam, de acumulação e ampliação da capacidade produtiva. Mão contrária do pressuposto dos estudos do desenvolvimento furtadianos, que se preocupam com as aspirações da coletividade para além dos objetivos econômicos. 
Gráfico 5 - Categoria Analítica: Caráter

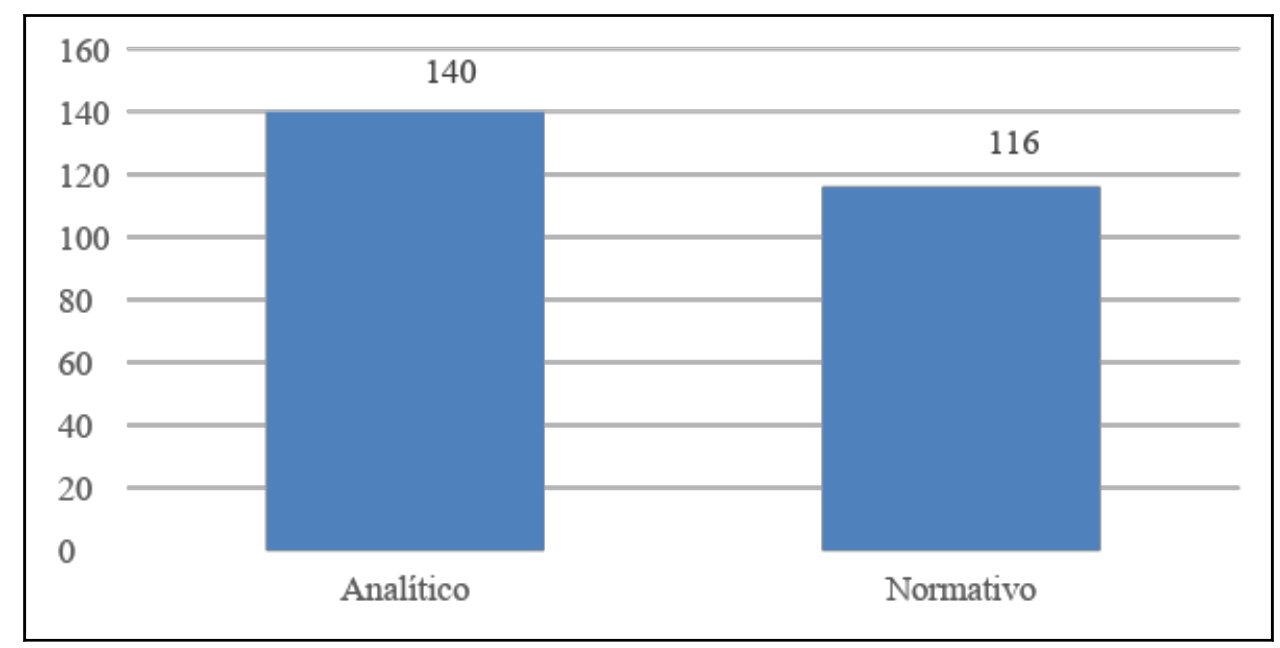

Fonte: Elaborado pelos autores (2019).

A quinta dimensão verificou o objetivo explicitamente indicado pelos autores nos artigos quanto ao seu caráter: analítico ou normativo. Nesse caso, houve o predomínio de trabalhos analíticos quem trata de um esquema de exposição e análise de processos em curso. A ideia de desenvolvimento furtadiana, contudo, aponta para o objetivo a ser perseguido, portanto, a partir de um princípio de avaliação (normativo) de formas de organização e de políticas para assim repensá-las. Dentro dessa perspectiva, a ideia de desenvolvimento vai além da eficácia do sistema produtivo, que reproduz uma sociedade desigual e de elevado potencial de acumulação de capital na mão de poucos nas nações periféricas.

Gráfico 6 - Categoria Analítica: Perspectiva Desenvolvimentista

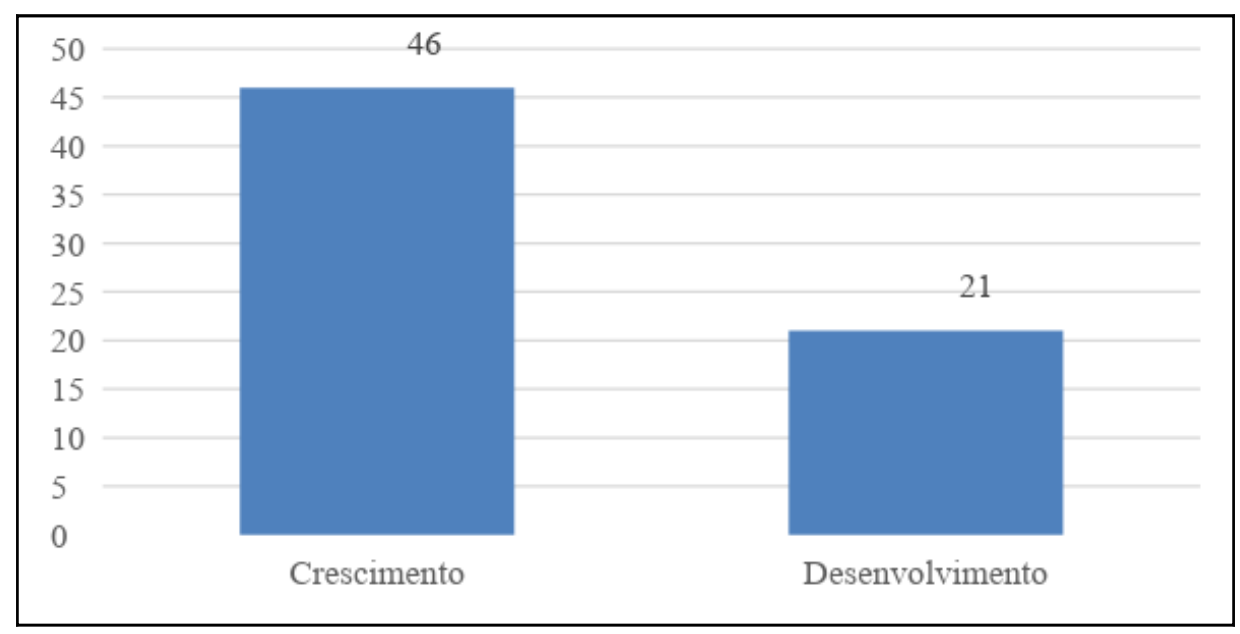

Fonte: Elaborado pelos autores (2019).

A penúltima dimensão tratava-se da perspectiva de desenvolvimento. Embora muitos trabalhos usassem o termo "desenvolvimento", tal conceito não se aproxima dos pressupostos de desenvolvimento apreendido por Celso Furtado. Os artigos davam ênfase à evolução do sistema produtivo e de acumulação de capital, aproximando-se da ideia de crescimento e não de desenvolvimento. 
Retomando a citação de Cohn (2015, p. 26), a dimensão do desenvolvimento e do crescimento são distintas, pois, para o crescimento "(...) prevalecem os princípios da eficiência e da rapidez de resposta" (COHN, 2015, p. 26), para o desenvolvimento “(...) prevalecem a deliberação e a reflexividade". Furtado (2002) defende que o desenvolvimento deve ser entendido como uma transformação no conjunto das estruturas sociais em benefício da coletividade e não deve ser confundido com a modernização dos padrões de consumo das minorias privilegiadas.

Por sua vez, a última dimensão - quanto à temática - buscou-se encontrar trabaIhos que tratavam das duas temáticas destacadas por Furtado, a saber: política consciente e ousada de fomento à criatividade humana e de controle dos recursos não renováveis de grande valor econômico e de dinamização do mercado interno nos países periféricos. A primeira temática - política consciente e ousada de fomento à criatividade humana - foi encontrada em apenas quatro artigos de um grupo de pesquisa. Por outro lado, não se identificou na amostra selecionada nenhum artigo que tratasse de políticas voltadas para o controle de recursos não renováveis, como o petróleo. O petróleo, por exemplo, é uma das principais fontes de poder nas relações internacionais, pelo qual os países periféricos podem tirar proveito e ter acesso ao mercado das nações dependentes. Assim, seria possível acumular recursos financeiros necessários para afirmar posições e ampliar o campo de resistência à dominação estrangeira (ALMEIDA, 2009). Nesse sentido, seria importante se debruçar sobre a temática dentro dos estudos da Administração.

Conclui-se, então, que apenas quatro artigos atenderam aos sete elementos do conceito de criatividade humana de Celso Furtado, tendo como objeto de estudo empresas sociais, defendendo o Estado como indutor de desenvolvimento, a partir de uma lógica que reavalie os fins, tendo como horizonte as necessidades da coletividade e o conceito de desenvolvimento por meio de uma abordagem normativa.

\section{CONSIDERAÇÕES FINAIS}

Procurou-se discutir ao longo do trabalho a importância das ações que venham a ser feitas em ciência, tecnologia e inovação para o desenvolvimento brasileiro. Assim, supomos que por meio da intelectualidade crítica é possível vislumbrar outras possibilidades de administração em contextos solidários, cooperativos, mediante parcerias entre pesquisadores e sindicatos, Organizações Não Governamentais, movimentos sociais, grupos sociais especialmente vulneráveis (imigrantes ilegais, desempregados, doentes crônicos, idosos, etc.), comunidades populares, grupos de cidadãos críticos e ativos.

A partir dessa premissa procuramos encontrar grupos de pesquisadores, dentro da Administração, comprometidos com a transformação dos contextos sociais - no âmbito das universidades e da produção de conhecimento - tendo como orientação o conceito de desenvolvimento de Celso Furtado, que levaria a criação intelectual a refletir sobre as transformações necessárias para levar o país ao desenvolvimento econômico e autonomia intelectual.

Entre os artigos selecionados e analisados (total 303), apenas quatro atendem ao conceito de criatividade humana de Celso Furtado. Diante dos achados desse trabalho, fica evidenciada a necessidade imperiosa de discutir e refletir mais e profundamente sobre o papel, o pensamento e o controle externo da universidade, dos grupos de pes- 
quisa e da produção científica visando ao desenvolvimento. Defende-se aqui, portanto, um esforço crítico de criação intelectual que objetiva a mudança na infraestrutura do país em termos de desenvolvimento.

Por outro lado, devemos registrar os limites deste trabalho, que podem originar futuros estudos. Naturalmente, é preciso reconhecer a ambição, talvez excessiva, de atribuir à universidade e aos intelectuais o protagonismo da mudança que se deseja, diante do jogo de forças no campo científico. Em consonância com as ideias de Bourdieu, sabe-se que os produtores culturais detêm um poder específico, qual seja, o poder de fazer com que se veja e que se acredite no mundo natural e no mundo social. Acredita-se, no entanto, que o texto represente um esforço inicial de delineamento do objeto e de criação de uma abordagem pertinente. Outra limitação foi gerada pelo recorte feito, que pode ter excluído trabalhos com as características buscadas.

O resultado final de um trabalho será sempre passageiro, parcial. Certamente, novas iniciativas de pesquisa serão necessárias para complementar tal esforço. Sugerem-se três possibilidades de desenvolvimento: (a) investigar a produção e atuação dos institutos federais espalhados por todo o Brasil, que trazem em seu cerne a preocupação com a comunidade em que atuam; e (b) acrescentar outros autores latino-americanos (como Aníbal Quijano, Arthuro Escobar, Enrique Dussel, Paulo Freire, entre outros) que se debruçam sobre a teoria decolonial, para uma renovação crítica e utópica das Ciências Sociais e (c) acrescentar na análise do campo científico a noção de habitus e de campo desenvolvida por Bourdieu, tendo em vista que este pode influenciar na tomada de posição dos atores.

Para fortalecer tal tratativa outros pesquisadores são encorajados a testarem esta lógica de raciocínio, bem como aplicá-la em recortes diferentes: regiões, universidades, áreas da Administração, instituições públicas e privadas, experiência dos pesquisadores ou novos entrantes.

\section{REFERÊNCIAS}

ALCADIPANI, R.; BERTERO, C. O. Os EUA e a exportação e a expansão do ensino de Management no Brasil nas décadas de 1950 e 1960. IV COLÓQUIO INTERNACIONAL DE EPISTEMOLOGIA E SOCIOLOGIA DA CIÊNCIA DA ADMINISTRAÇÃO, Florianópolis, 2014. Anais..., Universidade Federal de Santa Catarina, Florianópolis, 2014.

ALMEIDA, J. E. Subdesenvolvimento e dependência: uma análise comparada de Celso Furtado e Fernando Henrique Cardoso. 2009. Tese (Doutorado em Economia) - Faculdade de Ciências Econômicas, Universidade Federal do Rio Grande do Sul, Porto Alegre, 2009.

AZEVÊDO, A.; ALBERNAZ, R. O. A redução sociológica em status nascendi: os estudos literários de Guerreiro Ramos publicados na revista Cultura Política. Organizações \& Sociedade, Salvador, v. 17, n. 52, p. 47-68, jan./mar. 2010.

BARBOSA, L. Ponto crítico: conhecimento ou adestramento? Revista de Administração de Empresas Executivo, v. 1, n. 2, p. 80-84, 2003.

BARDIN, L. Análise de conteúdo. Lisboa: Edições 70, 229 p. 2011.

BERCOVICI, G. A questão social, a Constituição de 1988 e os desafios do desenvolvimento. In: SOUZA, Pedro de. (org.). Brasil, sociedade em movimento. São Paulo: Paz e Terra, 2015. p. 77-83.

BERTERO, C. O. Ensino e pesquisa em administração. São Paulo: Thomson, 2006.

BERTERO, C. O. et al. Produção científica brasileira em administração na década de 2000. RAE, São Paulo, V. 53, n. 1, jan./fev. 2013.

BERTERO, C. O.; CALDAS, M.; WOOD, T. Produção Científica em Administração de Empresas: Provocações, insinuações e contribuições para um debate local. Revista de Administração Contemporânea, v. 3, n. 1, jan./abr., 1999. p. 147-178. 
BOURDIEU, P. O ponto de vista do autor: algumas propriedades gerais dos campos de produção cultural. In: BOURDIEU, P. As regras da arte: gênese e estrutura do campo literário. São Paulo: Companhia das Letras, 1996. p. 243-316.

BOURDIEU, P. A distinção: crítica social do julgamento. São Paulo: Edusp; Porto Alegre: Zouk, 2007. p. 212239.

BUNGE, M. Ciência e desenvolvimento. Belo Horizonte: Itatiaia, 1980.

CARNEIRO, R. O. O desenvolvimento revisitado. São Paulo em Perspectiva, v. 20, n. 3, p. 73-82, jul./ago. 2006.

COORDENAÇÃO DE APERFEIÇOAMENTO DE PESSOAL DE NÍVEL SUPERIOR. CAPES - [online]. Disponível em: http://www.capes.gov.br/acessoainformacao/relatorios-anuais. 2016. Acesso em: 15 ago. 2016. CERVO, A. L. et al. Metodologia científica. 6. ed. São Paulo: Pearson Prentice Hall, 2007.

CHAIMOVICH, H. Brasil, ciência, tecnologia: alguns dilemas e desafios. Estudos Avançados, v. 14, n. 40, p. 134-143, 2000.

CHANLAT, J. F. Introdução. In: CHANLAT, J. F. Ciências sociais e management. São Paulo: Atlas, 1996.

COHN, G. Desenvolvimento como processo civilizador. In: SOUZA, Pedro de (org.). Brasil, sociedade em movimento. São Paulo: Paz e Terra, 2015. p. 25-30.

COSTA, F. L. da. Guerreiro Ramos: teoria e prática da sociologia em mangas de camisa. In: O Brasil em evidência: a utopia do desenvolvimento. Rio de Janeiro: FGV Editora, 2012. p. 472-485.

CONSELHO NACIONAL DE DESENVOLVIMENTO CIENTÍFICO E TECNOLÓGICO. CNPq. Distribuição dos grupos de pesquisa segundo a área do conhecimento predominante do grupo. Disponível em: http://lattes. cnpq.br/web/dgp/por-area. Acesso em: 8 jun. 2017.

CRISTALDO, R. C. Subdesenvolvimento, integração e administração política. Revista Brasileira de Administração Política. n. 2, v. 8, p. 85-110, out. 2015.

CUNHA, L. A. Educação e Desenvolvimento social no Brasil. Rio de Janeiro: F. Alves, 1980.

DANTAS, A. T.; MONFREDO, C. S. Celso Furtado: um intelectual brasileiro. In: O Brasil em evidência: a utopia do desenvolvimento. Rio de Janeiro: FGV Editora, 2012. p. 238-245.

FREIRE D'ÁGUIAR, Rosa. Apresentação. In: D'ÁGUIAR, Rosa Freire (org.). Celso Furtado e dimensão cultural do desenvolvimento. Centro Internacional Celso Furtado. Rio de Janeiro: E-papers, 2013. p. 2-9.

FURTADO, C. Criatividade e dependência na civilização industrial. São Paulo: Círculo do Livro, 1978.

FURTADO, C. Pequena introdução ao desenvolvimento: enfoque interdisciplinar. São Paulo: Nacional, 1980.

FURTADO, C. Metamorfose do capitalismo. 2002. Disponível em: http://www.redcelsofurtado.edu.mx/archivosPDF/furtado1.pdf. Acesso em: 3 jan. 2017.

FURTADO, C. Para onde caminhamos? 2004. Disponível em: http://www.centrocelsofurtado.org.br/arquivos/image/201411191728100.Dossier\%20CF\%2020\%20nov\%202014\%20ArtigoJBNovembro2004.pdf. Acesso em: jan. 2017.

GIL, A. C. Como elaborar projetos de pesquisa. 3. ed. São Paulo: Atlas, 1991.

GOODE, W. J.; HATT, P. K. Métodos em pesquisa social. 4. ed. São Paulo: Ed. Nacional, 1972.

GOULART, S.; CARVALHO, C. A. O caráter da internacionalização da produção científica e sua acessibilidade restrita. RAC, v. 12, n. 3, p. 835-853, 2008.

LEHER, R. Movimentos sociais, padrão de acumulação e crise da universidade. In: REUNIÃO DA ANPED, 37., 2015. Florianópolis. Trabalho Encomendado.

LEITÃO, C. Indústrias criativas x economia criativa: compreendendo a disputa entre modelos de desenvolvimento com base em Celso Furtado. In: SOUZA, Pedro de (org.). Brasil, sociedade em movimento. São Paulo: Paz e Terra, 2015. p. 150-165.

MARTINS, P. E. M. Alberto Guerreiro Ramos: um guerreiro exilado. In: MUNTEAL, Oswaldo; MARTINS, Paulo Emilio Matos (org.). O Brasil em evidência: a utopia do desenvolvimento. Rio de Janeiro: FGV Editora, 2012. p. 434-439.

MATTAR, F. N. Pesquisa de marketing: metodologia e planejamento. 6. ed. São Paulo: Atlas, 2005.

MOTTA, F. C. P. A questão da formação do administrador. RAE, Rio de Janeiro, v. 23, n. 4, out./dez. 1983.

NICOLINI, A. Qual será o futuro das fábricas de administradores? Fórum educação em administração. $R A E$, v. 43, n. 2, abr/maio/jun. 2003.

PAULA, A. P. P. de. Por uma nova gestão pública: limites e possibilidades da experiência contemporânea. Rio de Janeiro: FGV, 2005.

PINTO, M. M. Tecnologia e inovação. Apostila do curso de Administração Pública. Florianópolis: Universidade Federal de Santa Catarina, 2012. 
RAMOS, A. G. A redução sociológica. 3. ed. Rio de Janeiro: Editora UFRJ, 1958.

SAFATLE, V. O mito do desenvolvimento econômico na era Lula. In: SOUZA, Pedro de. (org.). Brasil, sociedade em movimento. São Paulo: Paz e Terra, 2015. p. 71-76.

SANTOS, E. L.; BRAGA, V.; SANTOS, R. S.; BRAGA, A. M. da S. Desenvolvimento: um conceito multidimensional. Desenvolvimento Regional em Debate. n. 1, v. 2, p. 44-61, jul. 2012.

SANTOS, B. S. A universidade do século XXI: para uma reforma democrática e emancipatória da universidade. São Paulo: Cortez, 2004. (Questões da nossa época, v. 120).

SOLE, A. Esta imagem da qual somos tão prisioneiros. Revista Gestão.Org, v. 1, n. 1, 2004.

STAKE, R. E. Case studies. In: DENZIN, N. K.; LINCOLN, Y. S. (edit.). Handbook of qualitative research. Thousand Oaks: Sage, 2000.

TENÓRIO, F. G. O drama de ser dois: um sociólogo engravatado. In: MUNTEAL, Oswaldo; MARTINS, Paulo Emilio Matos (org.). O Brasil em evidência: a utopia do desenvolvimento. Rio de Janeiro: FGV Editora, 2012. p. 440-471.

TRAGTENBERG, M. A delinquência acadêmica: o poder sem saber e o saber sem poder. São Paulo: Rumo Gráfica Editora, 1979.

VERGARA, Sylvia Constant. Projetos e relatórios de pesquisa em Administração. 6. ed. São Paulo: Atlas, 2005.

VIEIRA, M. M. F. Celso Furtado e o mito do desenvolvimento econômico. In: MUNTEAL, Oswaldo; MARTINS, Paulo Emilio Matos (org.). O Brasil em evidência: a utopia do desenvolvimento. Rio de Janeiro: FGV Editora, 2012. p. 230-237. 